\title{
Application of Fuzzy analytic hierarchy process to Multi-attribute Mining Craft Selection
}

\author{
R.L. SHAN ${ }^{1}$, C.Q. WANG ${ }^{1,2} \&$ X.G. CHEN ${ }^{1}$ \\ 1. School of Mechanics and Civil Engineering, \\ China University of Mining \& Technology, Beijing,100083, China; \\ 2. Datong Coal Mine Group, Datong 037003, China
}

\begin{abstract}
KEYWORD: Mining craft; Hesitancy degree; Vague sets; Decision
ABSTRACT: The decision information of mining craft selection is multi-attribute and fuzzy, so we propose a decision model by using Vague sets theory in this paper, the given score function considers the influence which is the hesitancy degree to the decision, the weight of attribute factors is determined by fuzzy hierarchy analysis method, then in order to improve the accuracy and safety of the decision, many experts contain in the model and the decision analysis is finally realize by using comprehensive score value and accuracy degree value. At last, using the above model make a instance analysis to a coal mine in Inner Mongolia. The result illustrate that this method is practical, and it can provides theory basis for the decision of the mining craft purification technology.
\end{abstract}

\section{introduction}

Although the coal resources are abundant in our country,its regional distribution is extremely uneven, geological structure, resources occurrence condition and regional economic development level are uneven, the allover coal resources mining condition is below the average level [1]. To realize the modernization more productive of the coal mine and more efficient construction, we must use the coal mining method of safe and reliable, feasible technology and considerable economic, and the mining technique is the most active factor among the coal mining method, due to the difference of the coal mining geological conditions and technical levels, so the technology economic effective is vary widely which is produced by the different mining craft and it is very important for coal mining process optimization [2]. For a long time, the selection of mining technique in our country, is only according to the actual situation of the coal mine and experiences of the technical personnel, as well as the cost of the technical and economic assessment of the coal mining equipment [3]. However, this decision means, obviously ignore the geological conditions of coal seam and some uncertainty factors which influences on the coal mining technology choice. In order to overcome the above disadvantages, some scholars make a study on the theory method of the mining craft. We take the method of fuzzy comprehensive evaluation to different geological conditions of coal seam mining process and give the appropriate degree value, as the according of the design planning and decision-making basis for mining technology [4]. It is combine with the specific coal mining established Coal process hierarchy model by using AHP method, through the analysis of the consistency check, determine the optimal scheme [5], for thick coal seam distance coal process optimization. The theory [6] of fuzzy information distribution establish a nonlinear mapping relationship between geological conditions and fully mechanized process, and achieve the purpose of reasonable mining technique to identify geological conditions. Then establish mining technique optimization model by using the method of grey situation decision-making, using the method make technical and economic comprehensive effect decision analysis to three coal mining of Shan Xi DaTong Mining Group.

Mining craft is one of the most link of the mine production, a reasonable choice have an important meaning to establish a high production and high effective mine. Technique need many indicators to make a comprehensive decision. However, there is no unified dimension among many indicators, and some information can comprehensive obtain until finishing craft [7]. To the relevant uncertain information decision problems,many scholars generally use the fuzzy set theory to deal it, but the effect is not ideal. Based on this, this paper presents a multiple attribute decision model which is based on the Vague set and make a decision analysis to a mine in ShanXi DaTong Mine Group of its mining craft optimal. 


\section{The basic theory of Vague sets}

Suppose $U$ is a domain, $x$ is denoted by any a element, $A$ is a Vague set on $U$ which is denoted by the true membership function $t_{A}$ and the false membership function $f_{A} \cdot f_{A}(x)$ is the negation membership which is derived from the evidence of against $x \in A$, and $t_{A}(x)+f_{A}(x) \leq 1$.We called $\left[t_{A}(x), 1-f_{A}(x)\right]$ is the Vague value of $x$ in Vague set $A$,write $x=\left[t_{A}(x), 1-f_{A}(x)\right]$,called

$\pi_{A}(x)=1-t_{A}(x)-f_{A}(x)$

is the unknown degree of $x$ for $A$, also called hesitation or hesitated degrees.

If $x=\left[t_{A}(x), 1-f_{A}(x)\right]$, the scoring function of Vague set $x$ is

$S_{A}(x)=t_{A}(x)-f_{A}(x)$

Accuracy function $H_{A}(x)=t_{A}(x)+f_{A}(x)$.

To promote

$$
\begin{aligned}
S_{A}^{*}(x) & =t_{A}(x)+\lambda_{1} \frac{t_{A}(x)}{t_{A}(x)+f_{A}(x)} \pi_{A}(x) \\
& -f_{A}(x)-\lambda_{1} \frac{f_{A}(x)}{t_{A}(x)+f_{A}(x)} \pi_{A}(x)
\end{aligned}
$$

Among the $\lambda_{1}$ is hesitant transformation parameters, $\lambda_{1} \in[0,1]$.

Assuing

$$
\begin{aligned}
x= & {\left[t_{A}(x), 1-f_{A}(x)\right], y=\left[t_{A}(y), 1-f_{A}(y)\right] . } \\
& \text { If } S_{A}^{*}(x)<S_{A}^{*}(y), \text { then } x<y ; \\
& \text { If } S_{A}^{*}(x)=S_{A}^{*}(y), \text { and } H_{A}(x)<H_{A}(y),
\end{aligned}
$$

then $x<y$.

A decision solution set $X=\left\{x_{1}, x_{2}, \mathrm{~L}, x_{n}\right\}$, a-ttribute set $G=\left\{g_{1}, g_{2}, \mathrm{~L}, g_{m}\right\}$ the weight of attribute set $W=\left\{w_{1}, w_{2}, \mathrm{~L}, w_{m}\right\}$, the scoring function is $S_{i j}^{*}\left(x_{i}\right)$ which is $x_{i}$ to $g_{j}$, the accuracy function is $H_{i j}\left(x_{i}\right)$, The final comprehensive scoring function of $x_{i}$ is

$$
S_{i}^{*}\left(x_{i}\right)=\sum_{j=1}^{m} w_{j} S_{i j}^{*}\left(x_{i}\right)
$$

and accuracy function is

$$
H_{i}\left(x_{i}\right)=\sum_{j=1}^{m} w_{j} H_{i j}\left(x_{i}\right)
$$

where $1 \leq i \leq n, 1 \leq j \leq m$.

\section{Fuzzy analytic hierarchy process}

Below is a solution for vector

$$
W=\left(w_{1}, w_{2}, \mathrm{~L}, w_{n}\right)^{\mathrm{T}}
$$

in an approximate calculation method: We all known that he corresponding matrix is

$$
A^{*}=\left(\frac{w_{i}}{w_{j}}\right)_{n \times n}=\left(a_{i j}^{*}\right)_{n \times n}
$$


here $w_{i}=\frac{1}{n} \sum_{j=1}^{n} \frac{a^{*}{ }_{i j}}{\sum_{k=1}^{n} a_{k j}{ }_{k j}}, i=1,2, \mathrm{~L}, n$.For the judgment matrix $A=\left(a_{i j}\right)_{n \times n}$ of the given, we can let $w_{i}=\frac{1}{n} \sum_{j=1}^{n} \frac{a_{i j}}{\sum_{k=1}^{n} a_{k j}}, i=1,2, \mathrm{~L}, n$;

Here, $W=\left(w_{1}, w_{2}, \mathrm{~L}, w_{n}\right)^{\mathrm{T}}$ as the weight vector . Based on $\sum_{j=1}^{n} a_{i j} w_{j}=\lambda_{i} w_{i},(i=1,2, \mathrm{~L}, n)$, gets $\lambda_{\max }=\frac{1}{n} \sum_{i=1}^{n} \frac{\sum_{j=1}^{n} a_{i j} w_{j}}{w_{i}}$

According to the judgment matrix $A$ to calculate the corresponding features solution $\lambda_{\max }$, in which $W$ is the weights of evaluation factors, consistency index $C I$ $=\left(\lambda_{\max }-n\right) /(n-1)$. The consistency test $C R=C I / R I$ is made finally, values of random consistency index RI can be seen in reference.

If $C R<0.10$, can be considered judgment matrix estimation is consistent, can accept.

If $C R \geq 0.10$, can be considered judgment matrix estimation is not very consistent, need to adjust the value of matrix, the new estimate.

In order to determine the weight of each attribute factor. At first, building the fuzzy consistent matrix, the so-called fuzzy consistent matrix $A=\left(a_{i j}\right)_{n \times n}$ refers to meet:

When listing facts use either the style tag List signs or the style tag List numbers.

(a) $0 \leq a_{i j} \leq 1(i, j=1,2, \ldots n)$;

(b) $a_{i j}+a_{j i}=1(i, j=1,2, \ldots, n)$;

(c) $\forall i, j, a_{i j}=w_{i}-w_{j}+0.5$.

If $A$ is the judgment matrix which is meet (a) and (b), we can calculate the weight $W$ by $w_{i}=\frac{1}{n}\left(\sum_{j=1}^{n} a_{i j}+1-\frac{n}{2}\right)$

Note when $\sum_{j=1}^{n} a_{i j} \leq \frac{n}{2}-1, A$ is not meet the consistency, then it need to alter, until it satisfied $w_{i} \geq 0$.

\section{Project instance analysis}

Three coal mines in Shanxi Tongmei Coal Group, for short called the coal mine one, the coal mine two, the coal mine three, respectively using one of the guns taken, conventional, high-grade conventional mining and fully mechanized. Decision scheme set, namely the mining technique

$X=\left\{x_{1}, x_{2}, x_{3}, x_{4}\right\}$,where $x_{1}$-Guns taken, $x_{2}$-conventional, $x_{3}$-high-grade conventional mining, $x_{4}$-fully mechanized. Attribute set associated with coal mining technology is

$G=\left\{g_{1}, g_{2}, g_{3}, g_{4}, g_{5}, g_{6}\right\}$, where $g_{1}$ - Coal mining working face of single production, $g_{2}$ Extraction efficiency, $g_{3}$ —investment in equipment, $g_{4}$ - mining costs, $g_{5}$ —adaptive degreegeological conditions, $g_{6}$ - the mechanization degree. The selected optimal solutions when make a decision to the mining face tend to consider single output as large as possible and extraction efficiency as large as possible, the equipment investment as small as possible, recovery cost as 
small as possible and adaptability as large as possible solutions and geological conditions, high mechanization degree as far as possible.

\section{The determination of decision matrix}

Now 20 experts evaluate the six properties of four schemes in three coal mines,respectively. The coal mine decision matrix $R^{(1)}, R^{(2)}, R^{(3)}$ As is shown below:

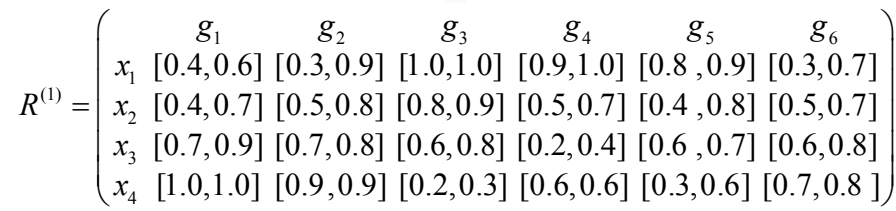

$R^{(2)}=\left(\begin{array}{ccccccc} & g_{1} & g_{2} & g_{3} & g_{4} & g_{5} & g_{6} \\ x_{1} & {[0.6,0.8]} & {[0.3,0.6]} & {[0.9,1.0]} & {[1.0,1.0]} & {[0.4,0.8]} & {[0.3,0.5]} \\ x_{2} & {[0.7,0.8]} & {[0.5,0.7]} & {[0.7,0.9]} & {[0.6,0.8]} & {[0.6,0.8]} & {[0.5,0.6]} \\ x_{3} & {[0.8,0.9]} & {[0.7,0.9]} & {[0.6,0.7]} & {[0.2,0.4]} & {[0.7,0.9]} & {[0.7,0.8]} \\ x_{4} & {[1.0,1.0]} & {[1.0,1.0]} & {[0.4,0.6]} & {[0.8,0.9]} & {[0.8,0.9]} & {[0.9,0.9]}\end{array}\right)$

$R^{(3)}=\left(\begin{array}{ccccccc} & g_{1} & g_{2} & g_{3} & g_{4} & g_{5} & g_{6} \\ x_{1} & {[0.5,0.7]} & {[0.2,0.5]} & {[0.9,1.0]} & {[0.9,0.9]} & {[0.6,0.8]} & {[0.3,0.6]} \\ x_{2} & {[0.6,0.8]} & {[0.3,0.6]} & {[0.7,0.8]} & {[0.5,0.7]} & {[0.5,0.7]} & {[0.4,0.7]} \\ x_{3} & {[0.7,0.9]} & {[0.6,0.8]} & {[0.4,0.6]} & {[0.3,0.5]} & {[0.7,0.9]} & {[0.7,0.8]} \\ x_{4} & {[1.0,1.0]} & {[0.9,1.0]} & {[0.2,0.5]} & {[0.7,0.9]} & {[0.8,0.9]} & {[0.9,1.0]}\end{array}\right)$

The score matrix and accuracy matrix

According to the score function formula and the accuracy function formula $R^{(1)}, R^{(2)}, R^{(3)}$ are applied to solve the data, then obtain the score matrix are $S^{*(1)} S^{*(2)} S^{*(3)}$, here $\lambda_{1}=1$.

$$
\begin{aligned}
& S^{*(1)}=\left(\begin{array}{ccccccc} 
& g_{1} & g_{2} & g_{3} & g_{4} & g_{5} & g_{6} \\
x_{1} & 0.00 & 0.50 & 1.00 & 1.00 & 0.78 & 0.00 \\
x_{2} & 0.14 & 0.43 & 0.78 & 0.25 & 0.33 & 0.25 \\
x_{3} & 0.75 & 0.56 & 0.50 & -0.30 & 0.33 & 0.50 \\
x_{4} & 1.00 & 0.80 & -0.56 & 0.20 & -0.14 & 0.56
\end{array}\right), \\
& S^{*(2)}=\left(\begin{array}{ccccccc} 
& g_{1} & g_{2} & g_{3} & g_{4} & g_{5} & g_{6} \\
x_{1} & 0.50 & -0.14 & 1.00 & 1.00 & 0.33 & -0.25 \\
x_{2} & 0.56 & 0.25 & 0.75 & 0.50 & 0.50 & 0.11 \\
x_{3} & 0.78 & 0.75 & -0.27 & -0.30 & 0.75 & 0.56 \\
x_{4} & 1.00 & 1.00 & 0.00 & 0.78 & 0.78 & 0.80
\end{array}\right) \text {, } \\
& S^{*(3)}=\left(\begin{array}{ccccccc} 
& g_{1} & g_{2} & g_{3} & g_{4} & g_{5} & g_{6} \\
x_{1} & 0.25 & -0.43 & 1.00 & 0.80 & 0.50 & -0.14 \\
x_{2} & 0.50 & -0.14 & 0.56 & 0.25 & 0.25 & 0.14 \\
x_{3} & 0.75 & 0.50 & 0.00 & -0.25 & 0.75 & 0.56 \\
x_{4} & 1.00 & 1.00 & -0.43 & 0.75 & 0.78 & 1.00
\end{array}\right) \text {, } \\
& H^{(1)}=\left(\begin{array}{ccccccc} 
& g_{1} & g_{2} & g_{3} & g_{4} & g_{5} & g_{6} \\
x_{1} & 0.80 & 0.40 & 1.00 & 0.90 & 0.90 & 0.60 \\
x_{2} & 0.80 & 0.70 & 0.90 & 0.80 & 0.60 & 0.80 \\
x_{3} & 0.80 & 0.90 & 0.80 & 0.80 & 0.90 & 0.80 \\
x_{4} & 1.00 & 1.00 & 0.90 & 1.00 & 0.70 & 0.90
\end{array}\right),
\end{aligned}
$$




$$
\begin{aligned}
H^{(2)} & =\left(\begin{array}{ccccccc} 
& g_{1} & g_{2} & g_{3} & g_{4} & g_{5} & g_{6} \\
x_{1} & 0.80 & 0.70 & 0.90 & 1.00 & 0.60 & 0.80 \\
x_{2} & 0.90 & 0.80 & 0.80 & 0.80 & 0.80 & 0.90 \\
x_{3} & 0.90 & 0.80 & 0.90 & 0.80 & 0.80 & 0.90 \\
x_{4} & 1.00 & 1.00 & 0.80 & 0.90 & 0.90 & 1.00
\end{array}\right), \\
H^{(3)} & =\left(\begin{array}{ccccccc} 
& g_{1} & g_{2} & g_{3} & g_{4} & g_{5} & g_{6} \\
x_{1} & 0.80 & 0.70 & 0.90 & 1.00 & 0.80 & 0.70 \\
x_{2} & 0.80 & 0.70 & 0.90 & 0.80 & 0.80 & 0.70 \\
x_{3} & 0.80 & 0.80 & 0.80 & 0.80 & 0.80 & 0.90 \\
x_{4} & 1.00 & 0.90 & 0.70 & 0.80 & 0.90 & 0.90
\end{array}\right) .
\end{aligned}
$$

\section{Determine the weight of attribute factors}

Firstly determine six attributes factors of fuzzy judgment matrix that are the coal mining work aspect of the single production, these are shown in Table 1.

\begin{tabular}{cccccc}
\multicolumn{7}{c}{ Table 1. Fuzzy judgment matrix } & \\
\hline$g_{1}$ & $g_{2}$ & $g_{3}$ & $g_{4}$ & $g_{5}$ & $g_{6}$ \\
\hline 0.5 & 0.4 & 0.6 & 0.3 & 0.7 & 0.5 \\
0.6 & 0.5 & 0.4 & 0.4 & 0.7 & 0.6 \\
0.4 & 0.6 & 0.5 & 0.5 & 0.4 & 0.7 \\
0.7 & 0.6 & 0.5 & 0.5 & 0.6 & 0.5 \\
0.3 & 0.3 & 0.6 & 0.4 & 0.5 & 0.6 \\
0.5 & 0.4 & 0.3 & 0.5 & 0.4 & 0.5 \\
\hline
\end{tabular}

According to the fuzzy analytic hierarchy process and we can get the weight vector $W=(0.101,0.203,0.235,0.215,0.130,0.116)$.

\section{Solution of the comprehensive score and precision value}

$$
\begin{aligned}
S_{1}^{*(1)}= & 0.2875 \times 0.00+0.3375 \times 0.50 \\
& +0.1875 \times 1.00+0.1875 \times 1.00 \\
= & 0.5438 \\
S_{2}^{*(1)}= & 0.2875 \times 0.00+0.3375 \times 0.43 \\
& +0.1875 \times 0.78+0.1875 \times 0.25 \\
= & 0.3383 . \\
S_{3}^{*(1)}= & 0.2875 \times 0.75+0.3375 \times 0.56 \\
& +0.1875 \times 0.50+0.1875 \times(-0.30) \\
= & 0.4421 . \\
S_{4}^{*(1)}= & 0.2875 \times 1.00+0.3375 \times 0.80 \\
& +0.1875 \times(-0.56)+0.1875 \times 0.20 \\
= & 0.4875 . \\
H_{1}^{(1)}= & 0.2875 \times 1.00+0.3375 \times 0.40 \\
& +0.1875 \times 1.00+0.1875 \times 0.90 \\
= & 0.7778 . \\
H_{2}^{(1)}= & 0.2875 \times 0.80+0.3375 \times 0.70 \\
& +0.1875 \times 0.90+0.1875 \times 0.80 \\
= & 0.7850 .
\end{aligned}
$$




$$
\begin{aligned}
H_{3}^{(1)}= & 0.2875 \times 0.80+0.3375 \times 0.90 \\
& +0.1875 \times 0.80+0.1875 \times 0.80 \\
= & 0.8338 . \\
H_{4}^{(1)}= & 0.2875 \times 1.00+0.3375 \times 1.00 \\
& +0.1875 \times 0.90+0.1875 \times 1.00 \\
= & 0.9813 .
\end{aligned}
$$

Similarly, you can find out other scoring value and accuracy.

\section{Determine the scheme}

According to the order of the comprehensive score of the coal mine One is $S_{1}^{*(1)}>S_{4}^{*(1)}>S_{3}^{*(1)}>S_{2}^{*(1)}$, so the coal mine One choose the gun taken; According to the order of the comprehensive score of the coal mine Two is $S_{4}^{*(2)}>S_{1}^{*(2)}>S_{2}^{*(2)}>S_{3}^{*(2)}$, So the coal mine Two choose fully mechanized coal mining process: According to the order of the comprehensive score of the coal mine Three is $S_{4}^{*(3)}>S_{1}^{*(3)}>S_{3}^{*(3)}>S_{2}^{*(3)}$, So coal mine Three choose fully mechanized coal mining technology.

\section{conclusions}

Conclusions should state concisely the most important propositions of the paper as well as the author's views of the practical implications of the results.

\section{Conclusion}

The paper according to the characteristics of many involved factors and partly incomplete information and fuzziness when we choose, using the theory of Vague set to make multiple attribute decision to the optimization of coal mining technology, attribute weights are determined by the fuzzy analytic hierarchy process, the calculate is simple, and the is same as the conclusion of the coal mine One use guns taken, coal mine Two and Three using fully mechanized coal.

\section{Reference}

[1]Jie Zhao. The present status of the coal mining technology in China and its research. Journal of shandong coal science and technology, 2010, (1):138-139.

[2]Xin Wen. The choice of underground coal mining technology and mining technique analysis. Energy and energy conservation, 2013,(8):3-5.

[3]Xianchen Zhang. Slowly inclined seam mining geological conditions of manufacturability evaluat Ion. Journal of China university of mining, 1991, 20 (3):35-44.

[4]Xianchen Zhang. Working face coal bed geological conditions of mining technology of fuzzy comprehensive evaluation. Journal of systems engineering, 2002,(3):252-256.

[5]Peng Liu. The selection of the thick coal seam mining technology based on AHP. Journal of shenhua science and technology, 2013, (5):47-49.

[6]Yushu Wei. The method of fuzzy information distribution and its application in coal mining technique selection. Journal of management science in China, 1999, 7(2):45-50.

[7]Yunbing Hou. Coal mining process evaluation and selection based on grey situation decision. Journal of mathematics practice and understanding, 2008, 42(5):66-70. 